\title{
Cenários da produção docente nas licenciaturas: desafios para uma universidade pública no Sul do Brasil
}

\author{
Valesca Brasil Iralai \\ Universidade Federal do Pampa, Bagé, RS, Brasil \\ Anderson Luis Jeske Bihain \\ Universidade Federal do Pampa, Porto Alegre, RS, Brasil
}

\begin{abstract}
Resumo
Este texto objetiva mapear, em uma instituição pública do Sul do Brasil, o cenário da produção docente no que tange à escolha dos veículos utilizados para socializar resultados de pesquisa, com ênfase nos professores dos cursos de licenciatura. Caracteriza-se como um estudo descritivo de dados extraídos da produção declarada por 400 docentes em um período de três anos (2016-2018). Identificaram-se os níveis de ensino predominantemente investigados (principalmente a Educação Básica), a área do conhecimento com maior produção (Ciências da Natureza) e os enfoques orientativos (Metodologias de Ensino e Formação de Professores - Inicial e Continuada). Também foi constatado que a maioria dos artigos foram publicados em língua portuguesa, bem como o padrão quantitativo dominante por docente foi de uma a cinco produções durante o período trienal analisado. Como prognóstico, indica-se a necessidade de serem pensados mecanismos para a formação continuada dos docentes universitários não apenas no âmbito do ensino, mas também no da pesquisa.
\end{abstract}

Palavras-chave

Ensino Superior. Formação de pesquisadores. Licenciatura. Produtividade científica.

\section{Scenarios of teaching written production in pre-service teacher education} programs: challenges for a public university in Southern Brazil

\begin{abstract}
This text aims to map, in a public institution in Southern Brazil, the scenario of teaching publication with regard to the choice of vehicles used to socialize research results, with an emphasis on professors of pre-service teacher education programs. It is characterized as a descriptive study of data extracted from the declared written production by 400 professors in a period of three years (2016-2018). The predominantly investigated levels of education were identified (mainly Primary and Higher School), the area of knowledge with the highest production (Natural Sciences) and guiding approaches (Teaching Methodologies and Teacher Education Programs). Also, it was found that most papers were published in Portuguese and the dominant quantitative standard per professor was 1 to 5 productions during the three-year period analyzed. As a prognosis, it is indicated for the need to think about mechanisms for the training of university professors not only in the scope of teaching, but also of research.
\end{abstract}

\section{Keywords}

University education. Training of researchers. Teacher education Programs. Scientific productivity.

Educ. Form., Fortaleza, v. 6, n. 2, e3982, maio/ago. 2021

DOI: https://doi.org/10.25053/redufor.v6i2.3982

https://revistas.uece.br/index.php/redufor/index 


\title{
Escenarios de producción docente en carreras de profesorado: desafíos para una universidad pública del Sur de Brasil
}

\begin{abstract}
Resumen
Este texto tiene como objetivo mapear, en una institución pública en el Sur de Brasil, el escenario de la producción docente con respecto a la elección de los vehículos utilizados para socializar los resultados de investigación, con énfasis en los docentes que actúan en carreras de formación docente. Se caracteriza como un estudio descriptivo de datos extraídos de la producción declarada por 400 profesores en un período de tres años (2016-2018). Se identificaron los niveles de educación predominantemente investigados (principalmente de la Educación Primaria y Secundaria), el área predominante de conocimiento (Ciencias Naturales) y los enfoques orientadores (Metodologías de enseñanza y formación del profesorado: inicial y continua). Además, se descubrió que la mayoría de los artículos se publicó en portugués y el estándar cuantitativo dominante por docentes fue de una a cinco producciones durante el período de los tres años analizados. Como pronóstico, se indica la necesidad de pensar en mecanismos para la educación continua de los profesores universitarios no solo en el campo de la enseñanza, sino también de la investigación.
\end{abstract}

\section{Palabras clave}

Enseñanza superior. Formación de investigadores. Profesorado. Productividad científica.

\section{Introdução}

Entre o conjunto plural de atividades produzidas no interior das universidades em diversas partes do mundo, uma das mais prestigiadas consiste naquelas que resultam em produções científicas socializadas em espaços/veículos legitimados e referendados pelos diferentes campos do conhecimento. Essa é, inclusive, uma das premissas estabelecidas para demarcar critérios de qualidade acadêmica, de forma a situar as diversas instituições não apenas em relação a suas dinâmicas internas, mas especialmente nos tensionamentos e diálogos que se dão em níveis mais amplos, por meio da construção e disseminação de estândares pautados em rankings globais entre países e entre instituições, reforçando uma lógica de ciência meramente produtivista (CUÑO BONITO, 2016; LOPES DA SILVA; MAIA FILHO; RABELO, 2019; MARCOVITCH, 2018).

Tais rankings utilizam diversas métricas e indicadores, que têm resultado em uma cobrança crescente sobre os pesquisadores, tanto em termos de qualidade quanto de quantidade das produções geradas, avaliadas pelo número de artigos publicados, comparações de desempenho por áreas do conhecimento, impacto de citações, colaborações nacionais e internacionais, entre outros aspectos considerados atualmente 
relevantes pela comunidade científica mundial (LAZCANO-PEÑA; VIEDMA; ALCAINO, 2019; SÁNCHEZ; URIBE; YEBRA, 2016; SANTOS, 2018). Na esteira dessas discussões gerais, cabe a cada instituição buscar reconhecer suas potencialidades e fragilidades no que diz respeito às suas próprias práticas de socialização do conhecimento, em especial porque, entre outras implicações, elas repercutem tanto na alocação de recursos financeiros quanto em visibilidade e reconhecimento coletivo (interno e externo) das ações institucionais (BARBA; CASTILLO; MASSARANI, 2019).

Ainda que vinculados a um contexto acadêmico específico, o da Universidade Federal do Pampa (Unipampa), entendemos que é possível estabelecer uma reflexão pertinente para pensar a produção do conhecimento que se dá no contexto da formação docente, já que a ênfase dos cursos tem sido cada vez mais a formação de professores pesquisadores em relação à sua prática pedagógica (GEVEHR; FETTER; KARPINSKI, 2019). Os cursos de formação de professores são, portanto, entendidos por nós como um campo estratégico, mas paradoxalmente são muitas vezes vistos como uma área desvalorizada em diversos espaços (políticos, midiáticos e mesmo acadêmicos, por agentes de áreas científicas percebidas como socialmente mais prestigiadas). Com este artigo, objetivamos mapear, nesse contexto institucional periférico, o cenário da produção docente no que tange à escolha dos veículos utilizados para socializar resultados de pesquisa, com ênfase nos professores dos cursos de licenciatura.

\section{Decisões e procedimentos metodológicos}

No contexto brasileiro, a denominação e a aglutinação de áreas do conhecimento são feitas por dois órgãos governamentais vinculados a dois ministérios distintos, a Coordenação de Aperfeiçoamento de Pessoal do Ensino Superior (Capes), atrelada ao Ministério da Educação, e o Conselho Nacional de Desenvolvimento Científico e Tecnológico (CNPq), atrelado ao Ministério da Ciência, Tecnologia, Inovações e Comunicações. Na Capes, por exemplo, coexistem como áreas independentes o "Ensino" (subordinado ao Colégio de Ciências Exatas, Tecnológicas e Multidisciplinar) e a "Educação" (vinculada ao Colégio de Humanidades). Pontuar as implicações desse desmembramento é relevante para pensar os limites e aproximações possíveis que se dão dentro de uma instituição - e fora dela - para qualificar a produção

Educ. Form., Fortaleza, v. 6, n. 2, e3982, maio/ago. 2021

DOI: https://doi.org/10.25053/redufor.v6i2.3982

https://revistas.uece.br/index.php/redufor/index ISSN: 2448-3583

(c) (i) Esta obra está licenciada com uma Licença Creative Commons 
científica vinculada aos processos educacionais e o quanto a complexidade dessas relações interfere em decisões e na formação de novas agendas e parcerias acadêmicas, facilitando ou dificultando a emergência de novos cenários.

O fato de a "Educação" e o "Ensino" terem se constituído historicamente como comunidades epistêmicas divergentes no contexto brasileiro, embora com movimentos de aproximações recentes (DIAS; THERRIEN; FARIAS, 2017; RAMOS; SILVA, 2014), tende a demonstrar algumas fragilidades contemporâneas derivadas dessas contingências. Essa separação obviamente traz efeitos para as pesquisas e para a criação/ampliação de cursos stricto sensu no âmbito das instituições, bem como sobre a identidade dos pesquisadores e seus alinhamentos teórico-metodológicos (e políticos).

Apesar de reconhecermos as implicações epistemológicas e políticas da distinção entre a área da Educação e a área do Ensino na estrutura de avaliação da pós-graduação no Brasil, abordaremos neste texto, para fins de análise, as produções docentes englobadas aqui por ambas as áreas, de forma indistinta. Fazemo-lo por duas razões principais: 1) por entender que a aproximação das áreas que olham para objetos que ora se sobrepõem e ora se aproximam pode contribuir para a criação de grupos de pesquisa que estabeleçam novos nichos e agendas distintas daquelas encontradas nas instituições mais tradicionais (o que pode atrair alunos de pós-graduação de diferentes regiões, por exemplo); 2) porque, no espaço investigado, uma instituição multicampi não departamentalizada, localizada em uma região periférica do país, geograficamente distante dos centros de pesquisa mais prestigiados, torna-se imperativo o desenvolvimento de projetos de pesquisa mais integrados e colaborativos, como forma de sobrevivência em um cenário nacional e internacional cada vez mais complexo e competitivo.

Dimensionamos este estudo no campo da pesquisa descritiva (TONETTO; BRUST-RENCK; STEIN, 2014). Para sumarizar a produção bibliográfica dos docentes que atuam na Unipampa, mais especificamente nos cursos de licenciatura, foi utilizado primeiramente o scriptLattes (MENA-CHALCO; CESAR-JR, 2009), que é um software livre de código aberto projetado para extrair dados do currículo de pesquisadores cadastrados na plataforma Lattes. O script é capaz de compilar automaticamente os dados de produção acadêmica de um ou diversos pesquisadores ao mesmo tempo, gerando como resultado uma série de tabelas e gráficos que demonstram como desenvolvem suas pesquisas e quem são seus colaboradores. 
Para realizar a análise de dados com 0 script, foi necessário fazer um levantamento no sistema de gestão institucional e verificar quais dos docentes da Unipampa haviam atuado nos cursos de licenciatura nos três anos elencados para a análise (entre 2016-2018), para posteriormente fazer o download das informações declaradas pelo Currículo Lattes de cada um deles, escrever e executar o algoritmo e, por sua vez, gerar o relatório bruto de produção acadêmica.

Optou-se por analisar, neste trabalho, de forma detalhada, exclusivamente a produção de artigos científicos. Após essa etapa, foram verificadas manualmente as possíveis duplicações de trabalhos e outras inconsistências nos dados, visto que um mesmo artigo produzido em colaboração por diferentes docentes (de um mesmo campus ou intercampi) apresentava sobreposição no relatório gerado automaticamente. De posse do relatório e limpeza de todas as inconsistências, foram identificados individualmente quais trabalhos abordavam temáticas relacionadas à Educação/Ensino, descartando aqueles que não tratavam desse escopo.

$\mathrm{Na}$ sequência da análise manual, entre os trabalhos remanescentes, também foram extraídas as temáticas e níveis de ensino mais contemplados nas pesquisas dos professores das licenciaturas. Para essa etapa, foram elencados três descritores que emergiram como significativos para cada artigo, a partir da consulta manual aos títulos, resumos e palavras-chave, bem como foi verificado se as revistas publicadas possuíam identificação de código DOI (Digital Object Identifier) e em quais idiomas os docentes costumam publicar. Primeiramente foram identificados 276 descritores diferentes, os quais foram reagrupados em 21 macrodescritores, para fins de uma melhor visualização e discussão dos dados.

\section{Resultados e discussão}

A primeira década dos anos 2000 foi marcada pela forte expansão das universidades públicas brasileiras (ARRUDA, 2011), sendo a Unipampa uma das instituições criadas para atender à política nacional de interiorização e democratização do Ensino Superior no Brasil, estabelecida naquela década (GENTIL, 2017). Nos seus primeiros anos, o foco foi exclusivo para as demandas em nível de graduação (em funcionamento desde 2006, embora a universidade tenha sido instituída oficialmente 
somente em 2008) e, a partir do ano de 2010, com a aprovação do primeiro curso de pós-graduação stricto sensu (UNIPAMPA, 2019).

Localizada na metade sul do Rio Grande do Sul, em municípios próximos ou fronteiriços com o Uruguai e a Argentina, a instituição foi desenhada para atender às demandas sociais de vários municípios de médio e pequeno porte da região. Ao todo, são 10 municípios com um campus universitário destinado ao ensino presencial e mais de 20 cidades em que foram instalados polos para a educação a distância, externos a alguma das cidades-sede da universidade.

O apelo para a questão regional esteve presente desde o início do discurso de criação da universidade, dado o diagnóstico das características identificadas pelo legado histórico, as quais, em um dado entendimento, contribuíram para um complexo quadro de estagnação estrutural (MARCHIORO et al., 2007), já que identificada "[...] como uma região predominantemente agropecuária, com base no latifúndio e na produção extensiva de gado ou em monoculturas agrícolas" (HOFF; MARTIN; SOPEÑA, 2011, p. 157-158).

Os cursos da área das licenciaturas desenvolvem um papel relevante e estratégico para alimentar o próprio discurso institucional em torno da missão de alavancar o desenvolvimento regional pela via educacional, especialmente se, a partir deles, for produzido conhecimento científico situado, demarcado a partir das problemáticas locais. Esse apelo está presente, por exemplo, no âmbito da pós-graduação, na opção pela oferta de mestrados na modalidade profissional destinados à formação continuada de professores da Educação Básica (DORNELLES; IRALA, 2019; LINDEMANN; LUCCHESE, 2015).

A expansão dos próprios cursos de licenciaturas dentro da Unipampa também é um indicador que comprova essa expectativa, já que, quando de sua criação, em 2006, apenas três dos 10 municípios possuíam cursos de licenciatura. Em contrapartida, hoje esse número ampliou-se para oito municípios com cursos na modalidade presencial. Já em se tratando do número de cursos, havia, na criação da universidade, apenas oito cursos de licenciatura; atualmente esse número chega a 21.

A consulta nos dados institucionais apontou que a Unipampa contava com 927 docentes (dados extraídos em dezembro 2018). Desse total, 827 contratados em regime de dedicação exclusiva/40 horas $(89,4 \%)$, além de 83 contratos temporários com regime 
de 20 horas de trabalho (9\%) e 15 com regime de trabalho de 40 horas $(1,6 \%)$. Ainda sobre o perfil acadêmico dos docentes, 700 possuem o título de Doutor $(75,6 \%)$, enquanto 176 são Mestres (19\%), 31 são Especialistas (3,4\%) e 19 possuem apenas o Ensino Superior (2,0\%). Desse total, 400 docentes ministraram algum componente curricular nos cursos de licenciatura da Unipampa no período compreendido entre 2016 e 2018.

Identificados os docentes que atuaram nos cursos de Licenciatura da Unipampa no período estabelecido, foi gerado, com o auxílio do scriptLattes, um relatório contendo os dados da produção acadêmica, o qual está disponibilizado e pode ser visualizado em Bihain (2019). Para a apresentação dos resultados, foi necessária uma detalhada análise manual de cada artigo, a fim de eliminar qualquer tipo de inconsistência de informação. A Tabela 1 apresenta um panorama real da dimensão da produção bibliográfica geral declarada pelos docentes que atuaram nos cursos de licenciatura da Unipampa entre os anos de 2016 e 2018 (vale ressaltar que esses dados foram extraídos em 2019).

Tabela 1 - Produção bibliográfica dos docentes dos cursos de licenciatura da Unipampa (2016-2018)

\begin{tabular}{ccc}
\hline Tipo de produção bibliográfica & Frequência de PB & \% de PB \\
\hline Artigos publicados em periódicos & 835 & 22,03 \\
Capítulos de livros publicados & 477 & 12,59 \\
Livros publicados/organizados ou edições & 127 & 3,35 \\
Resumos expandidos publicados em anais de congressos & 845 & 22,3 \\
Resumos publicados em anais de congressos & 855 & 22,56 \\
Trabalhos completos publicados em anais de congressos & 651 & 17,17 \\
\hline Total geral & $\mathbf{3 . 9 9 4}$ & $\mathbf{1 0 0}$ \\
\hline
\end{tabular}

Fonte: Elaboração dos autores (2019).

A Tabela 1 indica que o maior número de produções bibliográficas se vinculou, em porcentagens muito próximas, aos resumos publicados em anais de congresso e aos periódicos científicos. A preferência por publicações em periódicos se dá provavelmente pelo fato de que esse tipo de produção acadêmica tem um processo de avaliação mais prestigiado para a comunicação de resultados de trabalhos de pesquisa perante a comunidade científica (MUELLER, 2000), considerados como "[...] textos argumentativos altamente estratégicos" (MONTEMAYOR-BORSINGER, 2005, p. 215). Além disso, nos editais de processos seletivos para fomento de projetos de pesquisa, os artigos arbitrados em periódicos científicos recebem melhor pontuação e, por sua vez, então mais valorizados frente aos demais discursos acadêmico-científicos, assim como ocorre nas avaliações dos programas de pós-graduação. A Figura 1 expõe a 
frequência da produção bibliográfica dos professores das licenciaturas da Unipampa no período analisado.

Figura 1 - Frequência de produção bibliográfica dos professores dos cursos de licenciatura da Unipampa no período $2016-2018$

\section{Frequência de publicações}

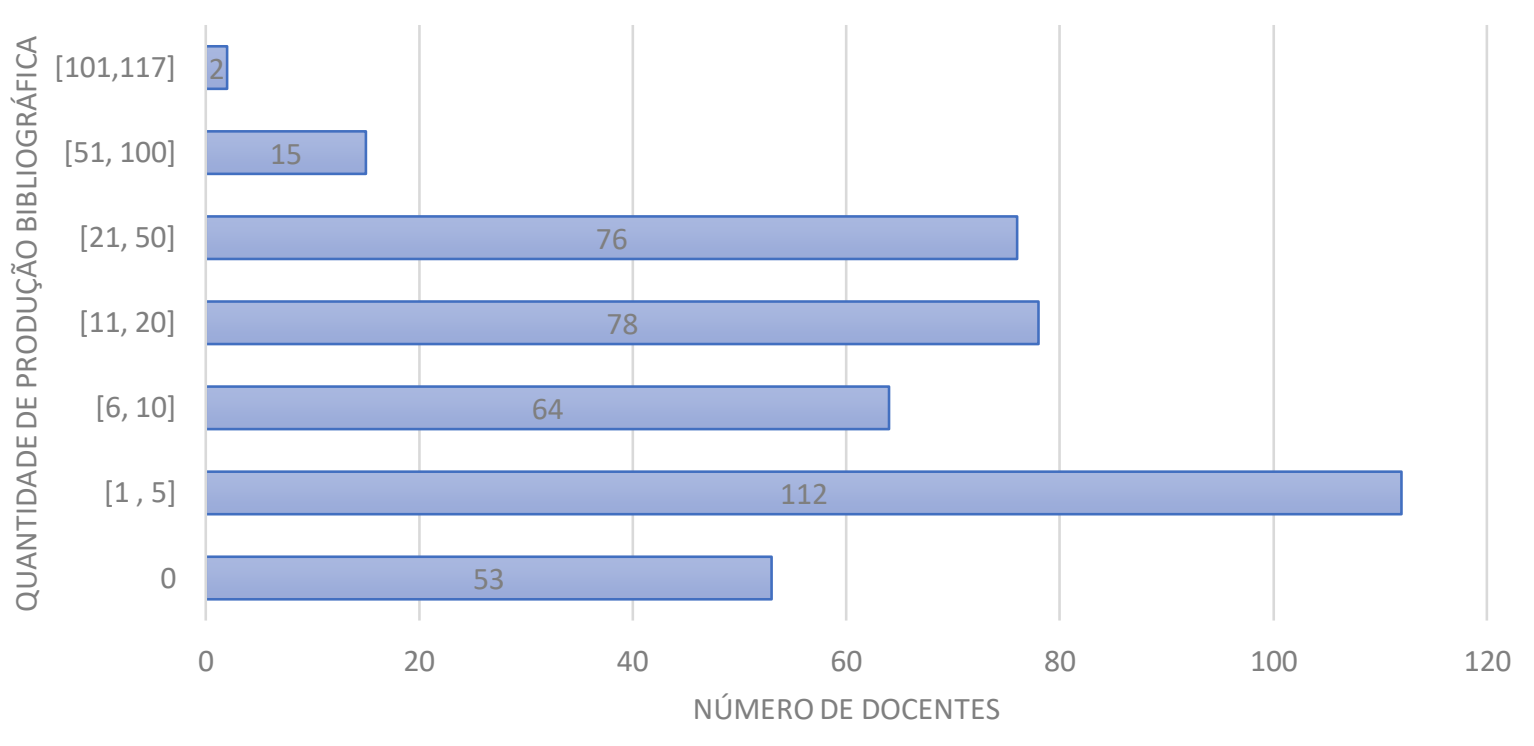

Fonte: Elaboração dos autores (2019).

Na Figura 1, entre os 400 docentes que tiveram seu Currículo Lattes analisado, $53(13,25 \%)$ não tiveram nenhum tipo de produção bibliográfica, enquanto 347 (86,75\%) docentes contabilizaram 3.994 itens publicados, o que dá uma média de 11,51 trabalhos por docente (ou seja, uma média de 3,83 por ano). A Figura 1 revela que há um número inexpressivo de docentes que apresenta uma produção muito mais elevada do que a maioria (dois docentes publicaram no período entre 101 e 117 trabalhos) e que o padrão predominante gira em torno de uma a cinco produções no período de três anos.

Quando analisada exclusivamente a produção de artigos publicados em periódicos científicos (Figura 2), constatou-se que 118 docentes (29,5\%) não haviam publicado artigos em periódicos científicos, enquanto 282 (70,5\%) pesquisadores haviam sido responsáveis pela publicação de 835 artigos em revistas do sistema Qualis/Capes, o que dá uma média de 2,96 artigos por docente (0,98 artigo por ano). 
Figura 2 - Frequência de publicação de artigos em periódicos científicos dos professores dos cursos de licenciatura da Unipampa no período 2016-2018

\section{Frequência de publicações em periódicos}

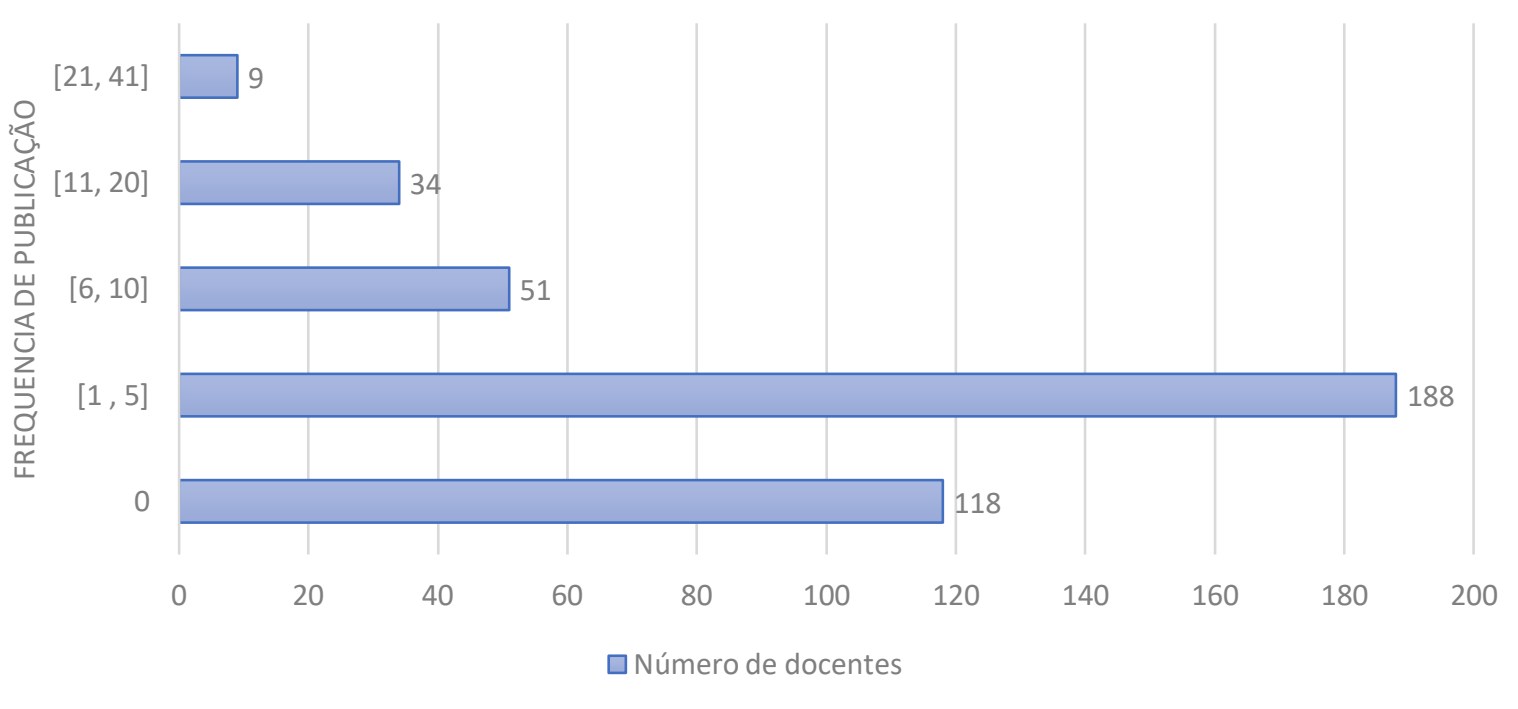

Fonte: Elaboração dos autores (2019).

Os dados revelam que a dispersão por outros tipos de produção bibliográfica ou a ausência de produções bibliográficas são relativamente expressivas entre os docentes que atuam nas licenciaturas da Unipampa. Contrapondo os dados apresentados na Figura 2 e o percentual de número de doutores no quadro de docentes da instituição, o qual ultrapassa $70 \%$, pode-se afirmar que a maior titulação não necessariamente refletiu em ampliação do percentual de publicações, indicando a necessidade de uma compreensão de natureza mais qualitativa para compreender os fatores que interferem nesse fenômeno: as responsabilidades assumidas pelos docentes em diversas atividades de caráter burocrático, o modelo de progressão na carreira adotado na instituição, entre outros fatores mais complexos que precisam ser analisados futuramente, através da geração de dados de natureza qualitativa junto a esses docentes.

Dos 282 docentes que haviam publicado artigos em periódicos, 131 (32,58\%) produziram 464 artigos com temáticas relacionadas à Educação (Tabela 2) e 511 relacionadas ao Ensino, de acordo com as áreas de avaliação do sistema Qualis/Capes, o que representa uma média de 2,85 artigos por pesquisador dentro do período analisado, ou seja, menos de um por ano. É importante mencionar que há um número expressivo de revistas que apresentam classificação nas duas áreas; portanto, com sobreposições nos dados.

Educ. Form., Fortaleza, v. 6, n. 2, e3982, maio/ago. 2021

DOI: https://doi.org/10.25053/redufor.v6i2.3982

https://revistas.uece.br/index.php/redufor/index 
Tabela 2 - Artigos publicados em periódicos com a classificação do sistema Qualis nas áreas de Educação e/ou Ensino

\begin{tabular}{ccc}
\hline Estrato & Qualis Educação & Qualis Ensino \\
\hline A1 & 21 & 31 \\
A2 & 34 & 50 \\
B1 & 59 & 105 \\
B2 & 70 & 102 \\
B3 & 40 & 37 \\
B4 & 51 & 47 \\
B5 & 76 & 51 \\
C & 68 & 7 \\
Qualis não identificado em & & 450 \\
nenhuma das duas áreas & & \\
(Educação ou Ensino) & &
\end{tabular}

Fonte: Elaboração dos autores (2019).

A Tabela 2 indica que 419 artigos apresentavam Qualis na área da Educação e 431 apresentavam Qualis na área do Ensino (a partir dos dados da classificação oficial ainda em vigor no período da extração de dados, a qual se balizou pelo quadriênio 20132016, pois a classificação das revistas nos novos estratos anunciados, que começou a ser disseminada no ano de 2019, de forma informal, não foi reconhecida como oficial pela Capes até o momento da análise). Além disso, é importante observar que apenas 62 docentes informaram no seu Currículo Lattes que sua área no CNPq é a área da Educação. Ou seja, esse dado indica que há um número maior de pesquisadores que efetuam algum tipo de pesquisa vinculada às áreas de Ensino/Educação, mas não exatamente têm formação e/ou atuação predominantes nessas áreas.

A Tabela 2 também revela que há um número muito elevado de pesquisas publicadas pelos docentes das licenciaturas sem nenhuma aderência às áreas de Educação/Ensino, o que pode ser depreendido quando se restringiu o algoritmo a selecionar os trabalhos catalogados apenas com Qualis em alguma das duas áreas e, portanto, excluindo as demais como "Qualis não identificado" para fins da análise efetuada. Esse dado coincide com o fato de que os docentes que apresentam maior número de produções não publicam nas temáticas de Ensino/Educação. Os dados revelam uma maior concentração de publicações nos estratos B1 e B2, no caso do Ensino, e ainda B5 e C, no caso da Educação. Esses dados apontam que há uma tendência de avaliação mais positiva do tipo de publicação efetuada pelos pesquisadores da instituição pela área do Ensino do que pela área da Educação, considerando também a natureza dos objetos de pesquisa mobilizados dos trabalhos publicados. 
Os dados apresentados na Figura 3 dizem respeito à presença de DOI nas revistas em que os artigos foram publicados e em quais línguas foram veiculadas essas publicações.

Figura 3 - Artigos com DOI x sem DOI e línguas de publicação

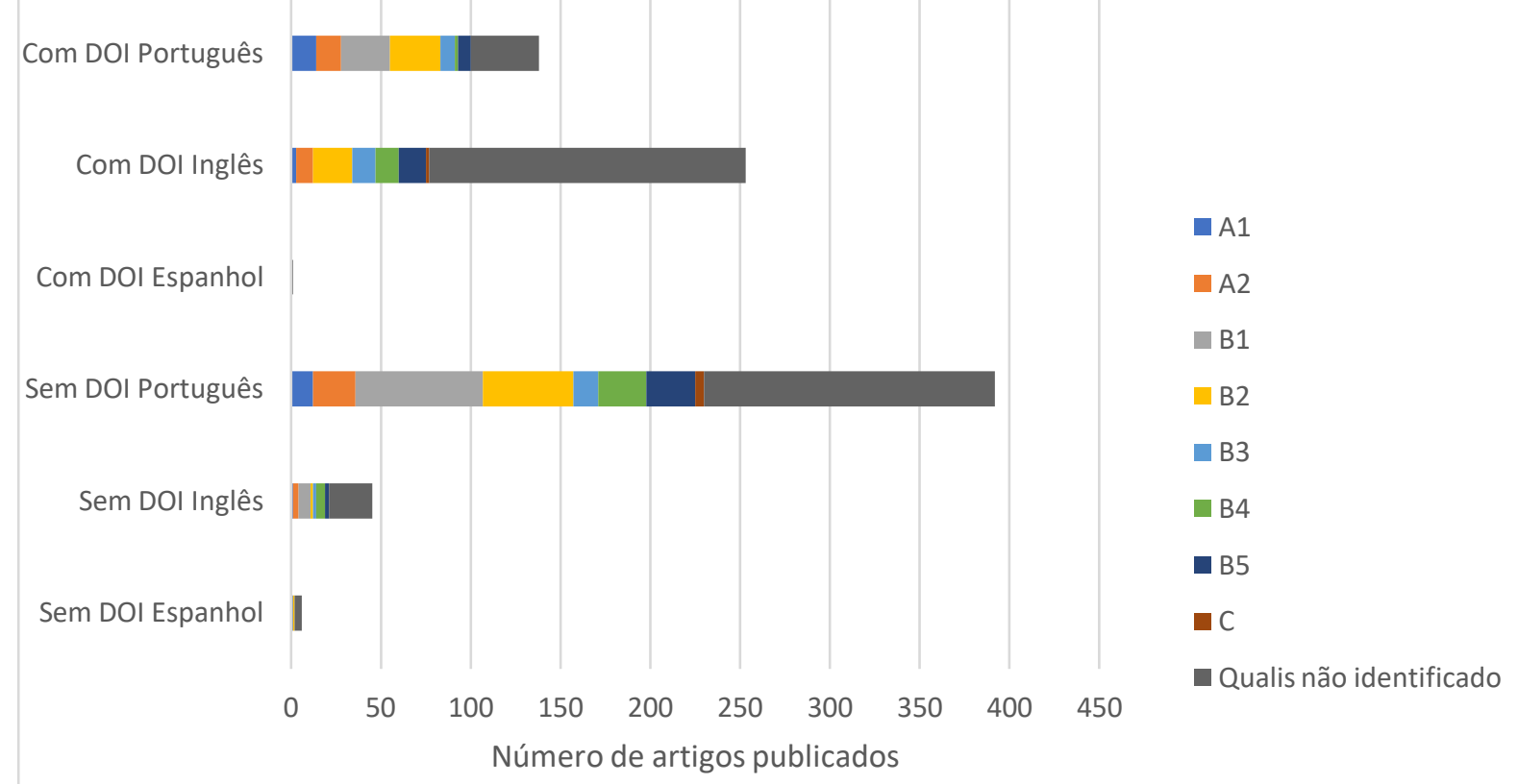

Fonte: Elaboração dos autores (2019).

Segundo Ferreira et al. (2015), os objetos digitais que possuem registro de DOI contribuem para a gestão de informações disponíveis na Internet, possibilitando a padronização e o cruzamento dos metadados, de modo a identificar mais facilmente quando, por exemplo, um texto acadêmico é acessado ou mesmo citado por outro trabalho em qualquer lugar do mundo. A CrossRef é uma Associação Internacional de Editores sem fins lucrativos, a qual tem sido uma das principais responsáveis por atribuir registros de $\mathrm{DOI}$ às publicações (não exclusivamente artigos). Para tanto, uma pessoa jurídica (por exemplo, uma revista) precisa se tornar membro da associação e se submeter aos direitos e deveres estipulados para tal.

Os dados revelam que, até o período em que os dados foram extraídos, muitas revistas, inclusive avaliadas nos melhores estratos, não apresentavam identificação de DOI (estando muitas delas em processo de adequação recente frente a essa demanda). Quando observadas as línguas de publicação dos artigos e estabelecida a relação com a 
presença ou não de DOI, constatou-se que os artigos publicados em português são os que menos apresentam a identificação pelo DOI e os artigos em inglês os que mais apresentam, independentemente se relacionados ou não às temáticas da Educação/ Ensino. Os dados também demonstram que a maioria dos professores que publicam na área da Educação/Ensino, no contexto da Unipampa, fazem-no em português e em revistas que não apresentavam DOI no momento da extração. Há ainda uma minoria inexpressiva que publica em espanhol.

Para identificar as temáticas, os níveis de ensino e as áreas de conhecimento preferenciais nas publicações dos docentes das licenciaturas que se dedicaram a pesquisar o campo educacional, foram extraídos primeiramente três descritores, alcançando um total de 276 diferentes nomenclaturas. Para uma melhor visualização dos resultados, os descritores iniciais foram reagrupados em outros 21 , sendo 20 deles os mais frequentes no conjunto de publicações. Um deles pôde ser considerado um descritor "coringa", pois resguardava todos os demais que não se adequavam dentro das características dos 20 descritores mais frequentes. A Figura 4 identifica os descritores (em destaque com letras maiores são apresentados aqueles que tiveram maior recorrência).

Figura 4 - Nuvem de palavras com descritores

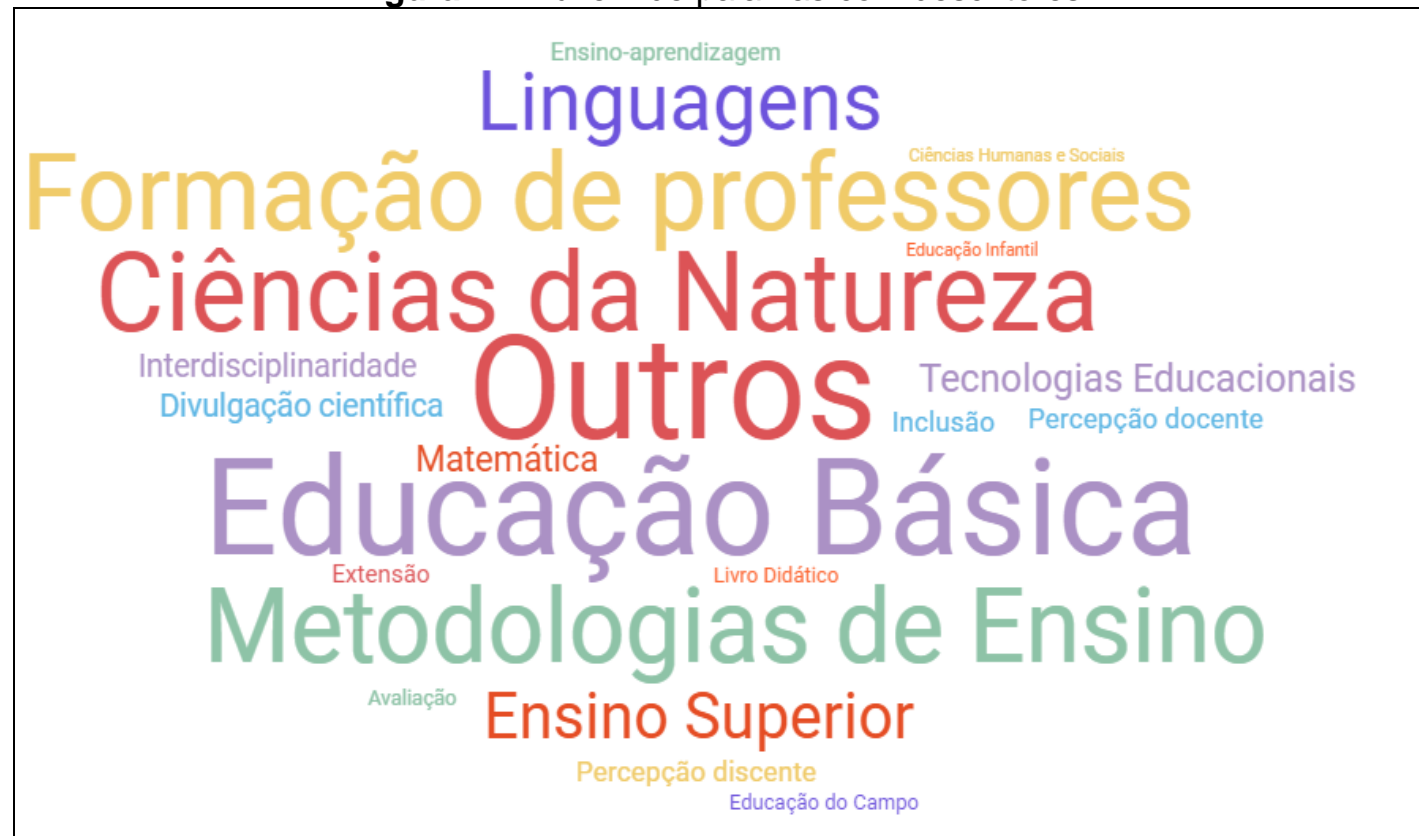

Fonte: Elaboração dos autores (2019).

Educ. Form., Fortaleza, v. 6, n. 2, e3982, maio/ago. 2021

DOI: https://doi.org/10.25053/redufor.v6i2.3982

https://revistas.uece.br/index.php/redufor/index 
Os dados evidenciam os campos do conhecimento e temáticas que mais fortemente disseminam os resultados de pesquisas vinculadas ao campo educacional por meio de artigos científicos, a saber, predominantemente a área de Ciências da Natureza, que reúne pesquisadores das áreas do Ensino de Química, de Física e de Biologia (essa última, com destaque especialmente no número de produções voltadas à Educação Ambiental). No que tange aos níveis de ensino, a Educação Básica tem sido prioritária como lócus de atuação das pesquisas desenvolvidas. O Ensino Superior aparece como um lócus emergente, especialmente quando se trata de pesquisas voltadas ao campo educacional produzidas por docentes com formação não advinda dos cursos de licenciatura, como, por exemplo, experiências no Ensino Superior nas áreas da Saúde, da Computação, da Geologia ou das Engenharias.

A formação de professores (seja inicial ou continuada) tem merecido atenção dos pesquisadores, bem como se destacam as pesquisas voltadas às metodologias de ensino (principalmente metodologias ativas), associadas ou não à utilização de tecnologias educacionais (em latente crescimento, ainda mais agora, no cenário que virá pós-pandemia da Covid-19). Podemos afirmar, portanto, que há uma forte tendência para a realização de pesquisas no campo da intervenção didática, tendo como lócus principal de geração de dados a própria sala de aula (presencial e/ou virtual), alinhando-se, assim, mais às discussões nacionais da área do Ensino do que da área da Educação.

Cabe citar como emergentes as pesquisas voltadas ao campo educacional na Unipampa às temáticas da divulgação científica, da extensão universitária e da inclusão, as quais têm se transversalizado com várias áreas do conhecimento. Cabe mencionar, por fim, a dispersão de focos de interesses dos pesquisadores, com a predominância de outros descritores que não puderam ser agrupados entre os mais frequentes, além da primazia do uso de metodologias qualitativas de pesquisa sobre as quantitativas.

\section{Considerações finais e prognósticos}

Os questionamentos iniciais que mobilizaram a escrita deste texto têm como pano de fundo a contribuição para o desenvolvimento de políticas institucionais voltadas ao fortalecimento das pesquisas no campo educacional, porém fica evidente que há elementos suprainstitucionais e supranacionais que produzem efeitos sobre o panorama 
mapeado, além de outras associações e reflexões mais profundas que os dados tenham revelado e que precisam ser aprofundadas em pesquisas futuras.

Na linha da reflexão realizada por Cuño Bonito (2016), os parâmetros e modelos internacionais estabelecidos como regra para os mais diferentes contextos institucionais mundo afora são definidos a partir de universidades como Harvard, Yale ou Stanford, as quais possuem um orçamento anual com cifras maiores do que até mesmo algumas nações do contexto latino-americano e provavelmente de outros continentes. Como aponta o autor, são essas instituições multimilionárias que vêm pautando a reconstrução de inúmeros parâmetros nas práticas atuais das publicações acadêmicas.

Podemos citar, em especial, a pressão pelo aumento do número de indexadores internacionais para as revistas, a obrigatoriedade do DOI, a exigência de vinculação ao Open Researcher and Contributor ID (Orcid) para os pesquisadores, a necessidade do uso da língua inglesa para o relato dos resultados de pesquisa, a fim de produzir textos com maior circulação, almejando um maior número de citações (sendo esse o principal parâmetro de qualidade estipulado, o que contraditoriamente exclui a "importância" de um conjunto de pesquisas criadas com foco em questões locais/regionais específicas, já que elas tendem a não ser objeto de interesse de pesquisadores internacionais, o que consequentemente gera um menor número de citações, etc.).

Todos esses elementos, alguns deles muito recentemente incorporados pelas políticas científicas nacionais e ainda em processo de "adequação" (haja vista que o Qualis/Capes oficialmente em vigor durante todo o quadriênio 2017-2020 foi o referente ao quadriênio de 2013-2016, havendo inclusive a possibilidade real de extinção do sistema Qualis a curto e médio prazos), são "novidades" para muitos professores, especialmente quando não estão vinculados a programas de pós-graduação. Além disso, é importante mencionar que algumas áreas do conhecimento tradicionalmente tinham como veículo prioritário de produção acadêmica os livros (individuais), as coletâneas com capítulos de diversos autores ou ainda a publicação em anais de eventos acadêmicos (áreas como, por exemplo, Letras, História, Sociologia, Música, entre outras). Recentemente, por todos os fatores já apontados, a pressão por abandonar a produção de livros e mesmo a publicação em anais para aderir quase que exclusivamente à produção de artigos parece imperativa também para essas áreas. Isso se mostra no esvaziamento, na perda de interesse na participação em eventos 
científicos e na redução sistemática das instituições e agências de fomento em apoio financeiro para essas ações, que décadas atrás eram frutíferos canais de disseminação científica e de produtivos debates acadêmicos.

Essa conjuntura emergente é condicionante de um aspecto fundamental para o desenvolvimento das pesquisas em todas as etapas: o financiamento. Se a disputa pelos recursos tem se tornado mais acirrada, as áreas do conhecimento que tradicionalmente estão alinhadas aos modelos implantados revelam-se como mais "atrativas" e supostamente mais produtivas, numa lógica amplamente disseminada de "política de resultados" (SOARES; COLARES, 2020), nos dois sentidos possíveis, em número de publicações e em possibilidades de atrair recursos econômicos, vinculados a possíveis parcerias entre as universidades e determinadas instituições nacionais ou estrangeiras.

$\mathrm{Na}$ esteira de todos esses aspectos, as pesquisas educacionais viabilizadas em instituições públicas periféricas como a Unipampa, desenvolvidas na Educação Básica e no Ensino Superior, ganham contornos de outra natureza (mesmo que nem sempre divulgadas nos veículos visivelmente mais prestigiados). Tornaram-se lócus de resistência, reinvenção e construção de possibilidades situadas, contribuindo para a resolução e compreensão de problemas locais/regionais, em contextos de múltiplas vulnerabilidades.

Como perspectiva futura, esperamos que, no contexto institucional analisado, haja a criação de espaços (presenciais ou virtuais) voltados a um planejamento coletivo de construção das ações de pesquisa nos cursos de licenciaturas, intencionando a ampliação de colaborações em projetos/grupos de pesquisa (ainda se identifica a presença de muitos trabalhos individuais nessas áreas ou de docentes em conjunto apenas com alunos, e não com outros colegas pesquisadores, como normalmente acontece em outros campos do conhecimento).

Além disso, são necessárias mais parcerias nacionais e internacionais, inclusive com os países latino-americanos mais próximos, com foco nas temáticas de interesse e com os mesmos princípios norteadores, e, por último, a criação necessária de estratégias de formação continuada de pesquisadores (incluindo, nesse aspecto em particular, elementos para qualificar a escrita acadêmica, não apenas em língua portuguesa, mas principalmente em uma perspectiva multilíngue). Por fim, ressaltamos que, apesar de haver uma política bem estabelecida para a formação continuada dos 
docentes universitários no que tange ao ensino, não identificamos equivalência dessas ações formativas no âmbito da pesquisa, a qual consideramos imperativa, dados os aspectos pontuados pela literatura e observados empiricamente.

\section{Referências}

ARRUDA, A. L. B. Políticas da Educação Superior no Brasil: expansão e democratização, um debate contemporâneo. Espaço do Currículo, João Pessoa, v. 3, n. 2, p. 501-510, 2011.

BARBA, M. L. P.; CASTILLO, J. P. G.; MASSARANI, L. Public engagement in Science: mapping out and understanding the practice of Science communication in Latin America. Anais da Academia Brasileira de Ciências, Rio de Janeiro, v. 91, n. 91, p. 1-16, 2019. Disponível em: https://doi.org/10.1590/0001-3765201920171000. Acesso em: 15 jul. $\underline{2020}$.

BIHAIN, A. Relatório gerado por scriptLattes V8.11. 2019. Disponível em: https://andersonbihain.github.io/forum licenciaturas/. Acesso em: 3 fev. 2020.

CUÑO BONITO, J. La universidad latinoamericana en la encrucijada: amenazas, desafíos y soluciones. Revista de Historia de la Educación Latinoamericana, Tunja, v. 18, n. 26, p. 241-277, 2016. Disponível em: http://dx.doi.org/10.19053/01227238.4374. Acesso em: 15 jul. 2020.

DIAS, A. M.; THERRIEN, J.; FARIAS, I. M. S. As áreas da educação e de ensino na Capes: identidade, tensões e diálogos. Revista Educação e Emancipação, São Luís, v. 10, n. 1, p. 34-57, 2017.

DORNELLES, C.; IRALA, V. B. Olhares para um mestrado profissional no Sul do Brasil. In: SILVA, W. R.; BEDRAN, P.; BARBOSA, S. A. (org.). Formação de professores de língua na pós-graduação. Campinas: Pontes, 2019. p. 155-187.

FERREIRA, E. et al. Digital Object Identifier (DOI): o que é, para que serve, como se usa? AtoZ: Novas Práticas em Informação e Conhecimento, Curitiba, v. 4, n. 1, p. 5-9, 2015. DOI: http://dx.doi.org/10.5380/atoz.v4i1.42369. Disponível em: https://revistas.ufpr.br/atoz/article/view/42369. Acesso em: 15 jul. 2020.

GENTIL, V. K. Expansão, interiorização e democratização do acesso à educação superior pública: o caso da Unipampa. 2017. 287 f. Tese (Doutorado em Educação) Programa de Pós-Graduação em Educação, Pontifícia Universidade Católica, Porto Alegre, 2017.

GEVEHR, D.; FETTER, S.; KARPINSKI, R. Produção do conhecimento na universidade: reflexões e incumbências em torno do trabalho de conclusão de curso. Educação \& 
Formação, Fortaleza, v. 4, n. 1, p. 131-147, 2019. DOI: https://doi.org/10.25053/redufor.v4i10.851. Disponível em: https://revistas.uece.br/index.php/redufor/article/view/851. Acesso em: 24 jan. 2021.

HOFF, D.; MARTIN, A. S.; SOPEÑA, M. Universidades e desenvolvimento regional: impactos quantitativos da Unipampa em Sant'Ana do Livramento. Redes, Santa Cruz, v. 16, n. 3, p. 157-183, 2011.

LAZCANO-PEÑA, D.; VIEDMA, G. C.; ALCAINO, T. V. Comunicación de la ciencia desde la mirada de los investigadores universitarios: entre el indicador y la vocación. Formación Universitaria, La Serena, v. 12, n. 6, p. 27-40, 2019. DOI: 10.4067/S0718-50062019000600027. Disponível em: https://scielo.conicyt.cl/scielo.php?script=sci arttext\&pid=S0718-50062019000600027. Acesso em: 15 jul. 2020.

LINDEMANN, R. H.; LUCCHESE, M. M. Ensino de Ciências na região da Campanha: reflexões iniciais de um processo de formação acadêmico-profissional de professores de Ciências. In: MARRANGHELLO, G. F.; LINDEMANN, R. H. (org.). Ensino de Ciências na região da Campanha: contribuições na formação acadêmico-profissional de professores de Química e Física. São Leopoldo: Oikos, 2015. p. 97-106.

LOPES DA SILVA, M.; MAIA FILHO, O.; RABELO, J. As condições de trabalho do professor universitário substituto na contemporaneidade: explorando a realidade de uma universidade pública. Educação \& Formação, Fortaleza, v. 5, n. 1, p. 215-234, 2019. DOI: https://doi.org/10.25053/redufor.v5i13.1002. Disponível em: https://revistas.uece.br/index.php/redufor/article/view/1002. Acesso em: 24 jan. 2021.

MARCHIORO, D. F. Z. et al. A Unipampa no contexto atual da educação superior. Avaliação, Sorocaba, v. 12, n. 4, p. 703-717, 2007.

MARCOVITCH, J. Monitoramento das métricas de desempenho acadêmico. In: MARCOVITCH, J. (org.). Repensar a universidade: desempenho acadêmico e comparações internacionais. São Paulo: Com-Arte, 2018. p. 95-110.

MENA-CHALCO, J. P.; CESAR-JR., R. M. ScriptLattes: an open-source knowledge extraction system from de Lattes platform. Journal of the Brazilian Computer Society, Porto Alegre, v. 15, n. 4, p. 31-39, 2009.

MONTEMAYOR-BORSINGER, A. Nueva taxionomía para elementos temáticos: aplicación al análisis de evolución autoral em artículos de investigación. Signo \& Seña, Buenos Aires, n. 14, p. 215-231, 2005.

MUELLER, S. P. M. O periódico científico. In: CAMPELLO, A.; CENDÓN, V.; KREMER, E. (org.). Fontes de informação para pesquisadores e profissionais. Belo Horizonte: UFMG, 2000. p. 73-96. 
RAMOS, C. R.; SILVA, J. A. A emergência da área de ensino de Ciências e Matemática da Capes enquanto comunidade científica: um estudo documental. Investigações em Ensino de Ciências, Porto Alegre, v. 9, n. 2, p. 363-380, 2014.

SÁNCHEZ, P. G.; URIBE, L. M. I.; YEBRA, J. M. Los indicadores de calidad y su relación con la ética en la producción académica. Estudio de casos comparados. Revista Iberoamericana para la Investigación y el Desarrollo Educativo, Guadalajara, v. 7, n. 13, p. 1-23, 2016.

SANTOS, S. Rankings internacionais de universidades: comparações e desempenho por áreas. In: MARCOVITCH, J. (org.). Repensar a universidade: desempenho acadêmico e comparações internacionais. São Paulo: Com-Arte, 2018. p. 63-94.

SOARES, L. V.; COLARES, M. L. I. S. Avaliação educacional ou política de resultados?. Educação \& Formação, Fortaleza, v. 5, n. 3, p. 1-24, 2020. Disponível em: https://revistas.uece.br/index.php/redufor/article/view/2951. Acesso em: 12 set. 2020.

TONETTO, L. M.; BRUST-RENCK, P. G.; STEIN, L. M. Perspectivas metodológicas na pesquisa sobre o comportamento do consumido. Psicologia: Ciência e Profissão, Brasília, DF, v. 34, n. 1, p. 180-195, 2014. DOI: https://doi.org/10.1590/S141498932014000100013. Disponível em: https://www.scielo.br/scielo.php?pid=S141498932014000100013\&script=sci abstract\&tlng=pt. Acesso em: 15 jul. 2020.

UNIPAMPA. Plano de Desenvolvimento Institucional 2019-2023. Bagé: Unipampa, 2019. Disponível em: https://sites.unipampa.edu.br/proplan/files/2019/09/pdi-2019-2023publicacao.pdf. Acesso em: 10 jun. 2020.

\footnotetext{
Valesca Brasil Irala, Universidade Federal do Pampa, campus Bagé, Mestrado Acadêmico em Ensino iDhttps://orcid.org/0000-0001-6190-8440

Professora associada 2 na Universidade Federal do Pampa (Unipampa). Doutora em Letras (Linguística Aplicada) pela Universidade Católica de Pelotas (UCPel), tendo feito seus estudos de pós-doutorado na Facultad de Humanidades y Ciencias de la Educación, na Universidad de la República (Uruguai). Atualmente atua no curso de graduação em Letras (Línguas Adicionais - Inglês e Espanhol) e no Mestrado Acadêmico em Ensino (MAE), no campus Bagé. Atualmente integra duas redes internacionais, a Assessment in Higher Education (AHE) Network e a Red Internacional de Evaluación Formativa y Compartida en Educación Superior (Refyces). É líder do Grupo de Pesquisa sobre Aprendizagens, Metodologias e Avaliação (Gama/registrado no Diretório de Grupos do CNPq), que apresenta uma perspectiva inter e transdisciplinar.

Contribuição de autoria: Concepção da pesquisa e construção da base teórica.

Lattes: http://lattes.cnpq.br/7316864301240506

E-mail: valescairala@unipampa.edu.br
}

Anderson Luis Jeske Bihain, Universidade Federal do Pampa, campus Bagé, Coordenação do curso de Matemática da Universidade Federal do Pampa

ii- https://orcid.org/0000-0002-9836-5926

Possui graduação em Matemática (licenciatura) pela Universidade Regional do Noroeste do Estado do Rio Grande do Sul (2008), mestrado em Modelagem Matemática (conceito Capes 4) pela Universidade Regional do Noroeste do Estado do Rio Grande do Sul (2011) e doutorado em Modelagem Computacional (conceito Capes 6) pela Universidade do Estado do Rio de Janeiro (2014). Atualmente é professor adjunto A da Universidade Federal do Pampa. Tem experiência na área de modelagem dos

Educ. Form., Fortaleza, v. 6, n. 2, e3982, maio/ago. 2021

DOI: https://doi.org/10.25053/redufor.v6i2.3982

https://revistas.uece.br/index.php/redufor/index 
fenômenos de trasporte, com ênfase em Modelagem de processos cromatográficos. Membro Grupo de Pesquisa sobre Aprendizagens, Metodologias e Avaliação (Gama/registrado no Diretório de Grupos do CNPq) e coordenador do curso de Matemática (licenciatura) da Universidade Federal do Pampa.

Contribuição de autoria: Escrita da metodologia, tabulação, limpeza, análise e visualização dos dados.

Lattes: http://lattes.cnpq.br/8636427420690720

E-mail: andersonbihain@unipampa.edu.br

Editora responsável: Lia Machado Fiuza Fialho

Pareceristas ad hoc: Daniela Pires e Gisela Steindel

\section{Como citar este artigo (ABNT):}

IRALA, Valesca Brasil; BIHAIN, Anderson Jeske. Cenários da produção docente nas licenciaturas: desafios para uma universidade pública no sul do Brasil. Educ. Form., Fortaleza, v. 6, n. 2, e3982, 2021. Disponível em:

https://revistas.uece.br/index.php/redufor/article/view/3982

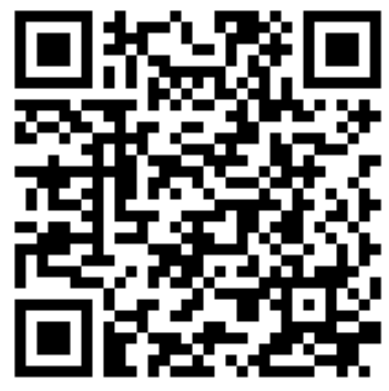

Recebido em 12 de outubro de 2020.

Aceito em 25 de janeiro de 2021.

Publicado em 25 de fevereiro de 2021. 